\title{
Association of gastrointestinal events with quality of life and treatment satisfaction in osteoporosis patients: results from the Medication Use Patterns, Treatment Satisfaction, and Inadequate Control of Osteoporosis Study (MUSIC OS)
}

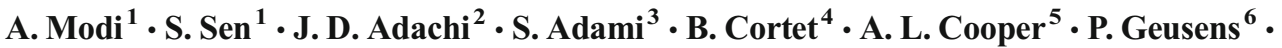 \\ D. Mellström ${ }^{7}$ - J. P. Weaver ${ }^{1}$. J. P. van den Bergh ${ }^{6,8}$ • P. A. Keown ${ }^{9} \cdot$ S. Sajjan ${ }^{1}$
}

Received: 7 March 2017 / Accepted: 7 June 2017 / Published online: 22 June 2017

(C) The Author(s) 2017. This article is an open access publication

\begin{abstract}
Summary The purpose of this study was to assess the association of GI events with HRQoL and treatment satisfaction. The effect of baseline GI events persisted through 1 year of follow-up, as indicated by lower EQ-5D, OPAQ-SV, and treatment satisfaction scores among patients with vs without baseline GI events. The presence of GI events is an independent
\end{abstract}

S. Adami and S. Sajjan are recently deceased.

Electronic supplementary material The online version of this article (doi:10.1007/s00198-017-4116-y) contains supplementary material, which is available to authorized users.

A. Modi

ankita.modi@merck.com

1 Center for Observational and Real-World Evidence (CORE), Merck \& Co., Inc., Kenilworth, NJ, USA

2 St Joseph's Healthcare and McMaster University, Hamilton, ON, Canada

3 Department of Medicine, University of Verona, Verona, Italy

4 Department of Rheumatology, University Hospital of Lille, Lille Cedex, France

5 Bridge Medical Center, Crawley, West Sussex, UK

6 Department of Rheumatology, Maastricht University Medical Center, Maastricht, The Netherlands

7 Department of Internal Medicine and Geriatrics, Gothenburg University, Gothenburg, Sweden

8 Department of Internal Medicine, VieCuri Medical Center, Venlo, The Netherlands

9 Syreon Corporation, Vancouver, Canada predictor of decreased HRQoL and treatment satisfaction in patients being treated for osteoporosis.

Introduction The goal of this study was to assess the association of gastrointestinal (GI) events with health-related quality of life (HRQoL) and treatment satisfaction in patients being treated for osteoporosis.

Methods MUSIC OS was a multinational, prospective, observational study examining the impact of GI events on osteoporosis management in postmenopausal women. In this analysis, HRQoL and treatment satisfaction were assessed at baseline, 6 , and 12 months and compared between patients with and without GI events. Covariateadjusted scores were calculated using multivariate leastsquares regression analysis, and differences between the mean scores of patients with and without baseline and post-baseline GI events were determined.

Results Among the 2959 patients in the analysis, unadjusted scores at each time point were lower (i.e., worse) for patients with GI events than patients without GI events. In adjusted analyses, the effect of baseline GI events persisted through 1 year of follow-up, as indicated by lower EQ-5D and OPAQ-SV scores at 12 months among patients with vs without baseline GI events $(-0.04$ for the EQ-5D utility score, -5.07 for the EQ-5D visual analog scale, -3.35 for OPAQ physical function, -4.60 for OPAQ emotional status, and -8.50 for OPAQ back pain; $P \leq 0.001$ for all values). Decrements in month 12 treatment satisfaction scores were -6.46 for patients with baseline GI events and -7.88 for patients with post-baseline GI events.

Conclusions The presence of GI events is an independent predictor of decreased HRQoL and treatment satisfaction in patients being treated for osteoporosis. 
Keywords Gastrointestinal diseases · Osteoporosis · Patient satisfaction $\cdot$ Postmenopausal $\cdot$ Quality of life

\section{Introduction}

Approximately $20 \%$ of European women and $11 \%$ of Canadian women aged 50 or older have osteoporosis [1,2]. Fully one third of the world's osteoporotic hip and vertebral fractures occur in Europe, resulting in approximately two million disability-adjusted life-years lost in the year 2000 [3]. This places the burden of osteoporosis in Europe above that of asthma, hypertensive heart disease, and most types of cancer [3].

Many studies have shown that osteoporosis-related fractures are associated with decreased health-related quality of life (HRQoL) [4-11]. A recent meta-analysis found that health state utility values of osteoporosis patients were reduced by 17-19\% after a fracture [12]. Evidence is mixed on whether and how much osteoporosis itself (i.e., in the absence of fracture) reduces quality of life [13], but some studies have found that femoral bone mineral density is associated with HRQoL $[14,15]$.

Pharmacologic treatment of osteoporosis is associated with improved HRQoL [7, 16-19]. However, global adherence to osteoporosis therapies is low [20]. This may be due to a variety of clinical- and patient-based factors, including gastrointestinal (GI) events, which are experienced by up to $52 \%$ of treated European osteoporosis patients [21-23]. GI events have been shown to affect HRQoL and treatment satisfaction in studies of US osteoporosis patients [24, 25]. However, there is limited evidence of this association in European patients.

The objective of this study was to determine the association of GI events with HRQoL and treatment satisfaction in osteoporosis patients in Europe and Canada, using data from the Medication Use Patterns, Treatment Satisfaction, and Inadequate Control of Osteoporosis Study (MUSIC OS).

\section{Methods}

\section{Study design}

The MUSIC OS-EU study was a prospective observational study conducted to examine the effect of GI symptoms on osteoporosis treatment, treatment satisfaction, and HRQoL in postmenopausal women in Europe and Canada [26]. The study was conducted in six countries-France, Italy, the Netherlands, Sweden, the UK, and Canada in accordance with the Declaration of Helsinki. Patient recruitment occurred between March 2012 and June 2013, and participants were followed for 12 months with outcomes recorded at baseline, 3,6 , and 12 months.

\section{Study sample}

Study participants were postmenopausal women $\geq 55$ years of age enrolled in physician clinics in one of the participating sites, which encompassed both primary care (58.3\%) and specialist $(41.7 \%)$ settings [26]. Each had a physician diagnosis of osteoporosis, was literate, was willing and able to follow the study protocol and complete all scheduled assessments, and provided informed consent.

Patients were excluded if they had been diagnosed with Parkinson's disease, any other neuromuscular diseases, or Paget's disease; were currently treated with any injected medication for osteoporosis; were considered by the investigator to be unwilling or unable to complete the study or comply with the protocol; were involved in any active litigation or compensation issues, including disability dispute cases with government; or were currently enrolled in a clinical trial or had participated in a clinical trial within the past 90 days.

\section{Osteoporosis treatment}

All patients had been prescribed treatment for their osteoporosis, which included bisphosphonates (e.g., alendronate, risedronate, and ibandronate), calcitonin, strontium ranelate, or selective estrogen-receptor modulators (raloxifene and bazedoxifene). Patients may also have been receiving calcium with or without vitamin D, estrogen, or hormone replacement therapy in addition to pharmacologic therapy for osteoporosis, but these agents were not by themselves considered pharmacologic treatment for this disorder.

Patients were classified as new users or experienced users of pharmacologic osteoporosis therapy. New users were defined as patients who had been receiving oral pharmacologic therapy for $<3$ months at the time of enrollment, with no prior history of any pharmacologic therapy for osteoporosis. Experienced users were defined as patients receiving the same oral pharmacologic therapy for $\geq 3$ months and continuing that treatment at the time of enrollment.

\section{Gastrointestinal symptoms}

GI events were self-selected from a list of symptoms which included heartburn/acid reflux, upset stomach/indigestion, nausea/vomiting, pain behind the breastbone, pain on swallowing or food sticking, stomach pain above or below the navel, diarrhea or constipation, and bloating. GI events were assessed by asking patients whether they had experienced any of the listed symptoms in the past 6 months (past 3 months at the 6-month time point). Answers were indicated with yes/no check boxes for each symptom. 


\section{Outcome measures}

Generic HRQoL was measured with the EuroQol 5dimension questionnaire (EQ-5D) [27]. The EQ-5D has two components: a utility score (scale 0 to 1.0 ), where 1.0 is defined as full health, and a visual analog scale (VAS; scale 0100), where 100 is the best imaginable health. The utility score comprises five dimensions (mobility, self-care, usual activities, pain/discomfort, and anxiety/depression) and is not bounded by a time frame, and the VAS assesses the patient's quality of life "today." The minimal clinically important difference (MCID) in the utility score, defined as the smallest change which patients perceive as beneficial and which would mandate a change in disease management, has been reported alternatively as 0.074 [28] and 0.03 [29].

Osteoporosis-specific quality of life was measured with the short version of the Osteoporosis Assessment Questionnaire (OPAQ-SV) [30]. The OPAQ-SV consists of 34 items in three domains (physical function, emotional status, and back pain), each with a scale of $0-100$. Higher scores indicate better quality of life. The time frame of the questionnaire is the previous 2 weeks.

Treatment satisfaction was measured with the Osteoporosis Patient Treatment Satisfaction Questionnaire (OPSAT-Q) [31]. The OPSAT-Q consists of 16 items on four subscales (convenience, confidence with daily functioning, overall satisfaction, and side effects). Subscale scores are used to create a composite satisfaction score that ranges from 0 to 100 , with higher scores indicating greater treatment satisfaction. The questions have no time frame of reference.

\section{Statistical analysis}

The study sample size was calculated to permit a final evaluable population of approximately 2700 subjects for the descriptive and exploratory analyses to permit comparisons between patients with and without GI events. Analyses of patient attrition at each time point showed that GI events did not influence the attrition rates.

Descriptive summaries of unadjusted scores for quality of life and treatment satisfaction were compiled at baseline, 6 months, and 12 months, and multiple linear regression analysis with backwards elimination was used to adjust for principal covariates. Covariates included in the full regression model, in addition to GI events, were age, body mass index (BMI), duration of treatment for osteoporosis at baseline, duration of osteoporosis at baseline, history of previous fractures, history of falls, concomitant medication use, comorbidities (including cardiac, endocrine, and GI disorders, metabolic and nutrition disorders, musculoskeletal diseases, vascular disorders, and malignant or benign neoplasms), pharmacologic treatment class (bisphosphonates or non-bisphosphonates), and, for analyses of all patients, user group (new or experienced).
GI events were categorized as (i) baseline, meaning they were reported on the baseline questionnaire, or (ii) post-baseline, meaning they were reported on either the month 6 or month 12 questionnaires, or both. Interaction terms were included for baseline and post-baseline GI events. Multivariate analyses of treatment satisfaction at baseline were not performed for new users since many were prescribed their first treatment at the baseline visit and thus could not complete these questions. The baseline results for "all patients" include the new users who were able to complete this component.

\section{Results}

\section{Baseline characteristics of study participants}

A total of 2959 patients were eligible for analysis at study entry, of which 684 were new users and 2275 were experienced users. Of these, 2545 patients remained eligible for analysis at month 12 of whom 535 were new users and 2010 were experienced users. The baseline demographic and clinical characteristics of the study sample have been reported elsewhere [32]. Briefly, the mean age of the study population was 69.4 years, and about half the patients $(49.4 \%)$ had a history of osteoporotic fracture. Overall, $79.9 \%$ of patients were taking bisphosphonates. A total of 2015 subjects $(68.1 \%)$ reported GI symptoms at baseline (new users 64.6\%; experienced users $69.1 \% ; P=0.03$ ) [32], and the cumulative frequency of subjects reporting GI events rose throughout the study, reaching $79.0 \%$ at month 6 (new users $79.6 \%$; experienced users $78.9 \%$ ) and $81.1 \%$ at month 12 (new users $81.5 \%$; experienced users $81.1 \%$ ) (manuscript in preparation). A total of 737 subjects $(25 \%)$ reported having one or more falls at baseline, with $39 \%$ reporting falls between baseline and month 12, and 1457 subjects (49.5\%) reported fractures at baseline with a further $1.8 \%$ between baseline and month 12 .

\section{Generic health-related quality of life: EQ-5D}

Mean unadjusted EQ-5D utility and VAS scores for all subjects were $0.81 \pm 0.18$ and $73.0 \pm 19.1$, respectively, at baseline, with no clinically important differences in either value between new and experienced users (EQ-5D score $0.81 \pm 0.18$ vs $0.80 \pm 17$; VAS $72.8 \pm 20.3$ vs $73.0 \pm 18.9$; data not shown). EQ-5D utility and VAS scores at baseline were lower by a clinically meaningful difference in both new users and experienced users with GI events than in those without GI problems and remained consistently lower throughout the 12month period of follow-up in both patient groups (Table 1).

When adjusted for influential variables, the baseline differences in the least-squares mean values between patients with and without GI events were highly significant $(-0.05$ for the 
EQ-5D utility score, $P<0.001$, and -5.61 for the VAS, $P<0.001$; Table 2). The effect of baseline GI events persisted through the entire year of follow-up, as indicated by the significant difference at both 6 and 12 months of patients with vs without baseline GI events ( -0.05 and -0.04 for utility scores and -5.22 and -5.07 for VAS; $P<0.001$ for all values; Table 2).

The occurrence of GI events after baseline was also an important predictor of reduced quality of life. Adjusted EQ$5 \mathrm{D}$ utility scores at 6 and 12 months $(-0.05$ and -0.05 , respectively, $P<0.001)$ and VAS scores at 6 and 12 months $(-3.49$ and -4.14 , respectively, $P<0.001)$ were significantly lower in patients who developed GI events during these intervals. Interaction terms (Table 2) indicated that reduction in the two EQ-5D measures was greatest in patients who reported GI events both prior to baseline and during the period of follow-up (utility score -0.08 and -0.07 at months 6 and 12 , $P<0.001$; VAS score -7.11 and 7.44 at months 6 and 12 , $P<0.001)$.

\section{Osteoporosis Assessment Questionnaire: OPAQ-SV}

Mean unadjusted OPAQ-SV scores for all subjects at baseline were $79.8 \pm 19.9$ for physical function (new users $80.9 \pm 19.5$, experienced users $79.5 \pm 20.0), 68.5 \pm 20.7$ for emotional status (new users $71.4 \pm 20.5$; experienced users $67.6 \pm 20.7$ ), and $62.8 \pm 27.7$ for back pain (new users $63.9 \pm 27.8$; experienced users $62.5 \pm 27.7$; data not shown). Physical function scores were marginally lower, while emotional status scores and back pain scores were more markedly reduced, in patients with GI events than in those without GI problems. Reported values remained consistently lower throughout the 12-month period of follow-up and appeared numerically greater among experienced than among new users (Table 1).

When adjusted for influential variables, the baseline differences in the least-squares mean values between patients with and without GI events were highly significant ( -3.53 for physical function, -5.55 for emotional status, and -10.11 for back pain, all $P<0.001$; Table 3). The effect of baseline GI events
Table 1 Unadjusted quality of life and treatment satisfaction scores at baseline, month 6 , and month 12 in patients with and without GI events at baseline

\begin{tabular}{|c|c|c|c|c|c|c|}
\hline & \multicolumn{3}{|c|}{ GI events at baseline } & \multicolumn{3}{|c|}{ No GI events at baseline } \\
\hline & Baseline & Month 6 & Month 12 & Baseline & Month 6 & Month 12 \\
\hline \multicolumn{7}{|l|}{ EQ-5D utility score } \\
\hline All patients & $0.79(0.18)$ & $0.80(0.18)$ & $0.80(0.18)$ & $0.85(0.17)$ & $0.86(0.16)$ & $0.85(0.18)$ \\
\hline New users & $0.79(0.18)$ & $0.81(0.19)$ & $0.81(0.17)$ & $0.84(0.17)$ & $0.86(0.15)$ & $0.86(0.17)$ \\
\hline Experienced users & $0.78(0.17)$ & $0.79(0.18)$ & $0.80(0.18)$ & $0.85(0.17)$ & $0.86(0.17)$ & $0.85(0.18)$ \\
\hline \multicolumn{7}{|l|}{ EQ-5D VAS score } \\
\hline All patients & $71.0(19.2)$ & $71.9(17.3)$ & $72.2(17.1)$ & $77.2(18.2)$ & $78.4(16.9)$ & $78.6(16.2)$ \\
\hline New users & $69.9(20.4)$ & $72.7(17.4)$ & $73.1(16.8)$ & $77.8(18.1)$ & $79.8(15.8)$ & $81.0(15.6)$ \\
\hline Experienced users & $71.3(18.8)$ & $71.7(17.3)$ & $72.0(17.2)$ & $77.0(18.2)$ & $77.9(17.3)$ & $77.9(16.3)$ \\
\hline \multicolumn{7}{|c|}{ OPAQ physical function } \\
\hline All patients & $78.2(20.3)$ & $78.1(21.3)$ & $77.8(21.5)$ & $83.2(18.6)$ & $84.2(18.5)$ & $83.2(19.9)$ \\
\hline New users & $80.0(19.2)$ & $80.4(20.0)$ & $79.6(20.6)$ & $82.6(19.9)$ & $84.0(18.1)$ & $84.3(19.7)$ \\
\hline Experienced users & $77.7(20.6)$ & $77.5(21.6)$ & $77.3(21.7)$ & $83.4(18.2)$ & $84.2(18.7)$ & $82.9(19.9)$ \\
\hline \multicolumn{7}{|l|}{ OPAQ emotional status } \\
\hline All patients & $66.1(20.7)$ & $65.8(21.8)$ & $65.5(22.0)$ & $73.6(19.9)$ & $73.1(20.6)$ & $72.3(21.4)$ \\
\hline New users & $69.5(20.1)$ & $68.5(20.9)$ & $67.9(21.2)$ & $75.0(20.6)$ & $75.3(19.2)$ & $75.1(20.4)$ \\
\hline Experienced users & $65.1(20.7)$ & $65.1(21.9)$ & $65.0(22.1)$ & $73.1(19.7)$ & $72.3(21.0)$ & $71.4(21.7)$ \\
\hline \multicolumn{7}{|l|}{ OPAQ back pain } \\
\hline All patients & $59.1(27.2)$ & $59.8(27.1)$ & $60.8(27.3)$ & $70.8(27.0)$ & $70.4(25.8)$ & $71.7(25.3)$ \\
\hline New users & $61.1(26.8)$ & $61.7(26.0)$ & $62.8(26.0)$ & $68.9(28.9)$ & $70.0(25.7)$ & $71.8(25.0)$ \\
\hline Experienced users & $58.5(27.3)$ & $59.3(27.4)$ & $60.3(27.7)$ & $71.5(26.4)$ & $70.6(25.8)$ & $71.7(25.4)$ \\
\hline \multicolumn{7}{|c|}{ OPSAT composite score } \\
\hline All patients & $78.6(15.1)$ & $78.0(15.6)$ & $77.3(16.3)$ & $84.6(13.4)$ & $84.2(13.5)$ & $84.4(13.7)$ \\
\hline New users & $75.0(16.0)$ & $76.7(16.4)$ & $77.3(15.4)$ & $82.0(12.2)$ & $83.0(13.9)$ & $84.6(13.3)$ \\
\hline Experienced users & $78.9(15.0)$ & $78.4(15.4)$ & $77.3(16.6)$ & $84.9(13.5)$ & $84.6(13.3)$ & $84.3(13.8)$ \\
\hline
\end{tabular}

Scores are mean (SD) values. GI event status is at baseline. There were 2943 patients in the analysis, 672 new users and 2271 experienced users

$E Q-5 D$ EuroQol 5 dimension questionnaire, OPAQ-SV Osteoporosis Assessment Questionnaire (short version), OPSAT Osteoporosis Patient Treatment Satisfaction Questionnaire, VAS visual analog scale 
Table 2 Least-squares mean differences in EQ-5D between patients with and without GI events at baseline, month 6, and month 12

\begin{tabular}{|c|c|c|c|c|c|c|}
\hline & \multicolumn{2}{|l|}{ Baseline } & \multicolumn{2}{|l|}{ Month 6} & \multicolumn{2}{|l|}{ Month 12} \\
\hline & $\begin{array}{l}\text { LS mean difference } \\
(95 \% \mathrm{CI})\end{array}$ & $P$ & $\begin{array}{l}\text { LS mean difference } \\
(95 \% \mathrm{CI})\end{array}$ & $P$ & $\begin{array}{l}\text { LS mean difference } \\
(95 \% \mathrm{CI})\end{array}$ & $P$ \\
\hline \multicolumn{7}{|l|}{ EQ-5D utility } \\
\hline $\begin{array}{l}\text { Baseline GI problems vs no } \\
\text { baseline GI problems }\end{array}$ & $-0.05(-0.065,-0.039)$ & $<0.001$ & $-0.05(-0.062,-0.034)$ & $<0.001$ & $-0.04(-0.055,-0.026)$ & $<0.001$ \\
\hline GI event BL to M6 & - & - & $-0.05(-0.064,-0.033)$ & $<0.001$ & $-0.05(-0.066,-0.034)$ & $<0.001$ \\
\hline $\mathrm{GI}(\mathrm{BL} \text { to } \mathrm{M} 6)^{*} \mathrm{GI}(\mathrm{BL}=\mathrm{Y})$ & - & - & $-0.08(-0.092,-0.059)$ & $<0.001$ & $-0.07(-0.086,-0.052)$ & $<0.001$ \\
\hline $\mathrm{GI}(\mathrm{BL} \text { to } \mathrm{M} 6)^{*} \mathrm{GI}(\mathrm{BL}=\mathrm{N})$ & - & - & $-0.04(-0.067,-0.019)$ & $<0.001$ & $-0.04(-0.067,-0.018)$ & $<0.001$ \\
\hline GI event BL to M12 & - & - & - & - & $-0.05(-0.068,-0.035)$ & $<0.001$ \\
\hline GI $(\mathrm{BL} \text { to } \mathrm{M} 12)^{*} \mathrm{GI}(\mathrm{BL}=\mathrm{Y})$ & - & - & - & - & $-0.07(-0.088,-0.053)$ & $<0.001$ \\
\hline $\mathrm{GI}(\mathrm{BL}$ to $\mathrm{M} 12) * \mathrm{GI}(\mathrm{BL}=\mathrm{N})$ & - & - & - & - & $-0.05(-0.074,-0.026)$ & $<0.001$ \\
\hline \multicolumn{7}{|l|}{ EQ-5D VAS } \\
\hline $\begin{array}{l}\text { Baseline GI problems vs no } \\
\text { baseline GI problems }\end{array}$ & $-5.61(-7.076,-4.146)$ & $<0.001$ & $-5.22(-6.613,-3.823)$ & $<0.001$ & $-5.07(-6.437,-3.705)$ & $<0.001$ \\
\hline GI event $\mathrm{BL}$ to $\mathrm{M} 6$ & - & - & $-3.49(-5.034,-1.942)$ & $<0.001$ & $-4.31(-5.817,-2.797)$ & $<0.001$ \\
\hline $\mathrm{GI}(\mathrm{BL} \text { to } \mathrm{M} 6)^{*} \mathrm{GI}(\mathrm{BL}=\mathrm{Y})$ & - & - & $-7.11(-8.784,-5.437)$ & $<0.001$ & $-7.44(-9.075,-5.811)$ & $<0.001$ \\
\hline $\mathrm{GI}(\mathrm{BL} \text { to } \mathrm{M} 6)^{*} \mathrm{GI}(\mathrm{BL}=\mathrm{N})$ & - & - & $-1.99(-4.386,0.401)$ & 0.103 & $-3.44(-5.780,-1.102)$ & 0.004 \\
\hline GI event BL to M12 & - & - & - & - & $-4.14(-5.705,-2.567)$ & $<0.001$ \\
\hline $\mathrm{GI}(\mathrm{BL} \text { to } \mathrm{M} 12)^{*} \mathrm{GI}(\mathrm{BL}=\mathrm{Y})$ & - & - & - & - & $-7.29(-8.985,-5.603)$ & $<0.001$ \\
\hline $\mathrm{GI}(\mathrm{BL}$ to $\mathrm{M} 12) * \mathrm{GI}(\mathrm{BL}=\mathrm{N})$ & - & - & - & - & $-3.41(-5.669,-1.156)$ & 0.003 \\
\hline
\end{tabular}

Results are for new users and experienced users combined

$B L$ baseline, $E Q-5 D$ EuroQol 5-dimension questionnaire, GI gastrointestinal, M6 month 6, M12 month 12, VAS visual analog scale

persisted through the entire year of follow-up (Table 3), as shown by the significant difference at both 6 and 12 months of patients with vs those without baseline GI events $(-4.55$ and -3.35 for physical function, -5.55 and -4.60 for emotional status, and -8.66 and -8.50 for back pain; all $P<0.001$ ).

The occurrence of GI events after baseline was also an important predictor of reduced quality of life measured by OPAQ-SV (Table 3). Adjusted scores for physical function (6 months $-3.85, P<0.001 ; 12$ months $-2.98, P<0.002$ ), emotional status $(6$ months $-5.20, P<0.001 ; 12$ months $-5.35, P<0.001)$, and back pain (6 months -7.01 , $P<0.001 ; 12$ months $-6.93, P<0.001)$ were significantly lower in patients who developed GI events during these intervals. The differences in all three OPAQ-SV measures were greatest among patients who reported GI events both prior to baseline and during the period of follow-up (physical function -6.80 and -4.83 at months 6 and $12, P<0.001$; emotional status -8.33 and -7.38 at months 6 and $12, P<0.001$; and back pain -12.55 and -12.27 at months 6 and $12, P<0.001$ ).

\section{Osteoporosis Patient Treatment Satisfaction Questionnaire}

The mean unadjusted composite treatment satisfaction score for all subjects at baseline was $80.5 \pm 14.9$ (new users $77.6 \pm 15.0$ and experienced users $80.8 \pm 14.8$; data not shown). As shown in Table 1, the score was lower in patients with than in those without GI events at baseline and remained so throughout follow-up (78.6 vs 84.6 at baseline, 78.0 vs 84.2 at 6 months, and 77.3 vs 84.4 at 12 months).

When adjusted for influential variables, the baseline difference in the least-squares mean values between patients with and without GI events was highly significant $(-5.88$, $P<0.001$; Table 4). The effect of baseline GI events persisted throughout follow-up (Table 4), with a significant difference at both 6 and 12 months between patients with or without baseline GI events $(-5.89$ and -6.46 , both $P<0.001)$.

As observed with the other measures, adjusted scores were also significantly lower in patients who reported GI events after baseline (6 months $-6.83, P<0.001 ; 12$ months -7.88 , $P<0.001)$. The differences were greatest among patients who reported GI events both prior to baseline and during the period of follow-up ( -9.21 and -10.59 at months 6 and 12, both $P<0.001)$ (Table 4).

\section{Other covariates influencing health outcome measures}

Certain demographic and clinical factors other than GI events also influenced the health outcome measures recorded (Online Resource Tables 1, 2, 3, 4, 5, 6). 
Table 3 Least-squares mean differences in OPAQ-SV between patients with and without GI events at baseline, month 6, and month 12

\begin{tabular}{|c|c|c|c|c|c|c|}
\hline & \multicolumn{2}{|l|}{ Baseline } & \multicolumn{2}{|l|}{ Month 6} & \multicolumn{2}{|l|}{ Month 12} \\
\hline & $\begin{array}{l}\text { LS mean difference } \\
(95 \% \mathrm{CI})\end{array}$ & $P$ & $\begin{array}{l}\text { LS mean difference } \\
(95 \% \mathrm{CI})\end{array}$ & $P$ & $\begin{array}{l}\text { LS mean difference } \\
(95 \% \mathrm{CI})\end{array}$ & $P$ \\
\hline \multicolumn{7}{|l|}{ Physical function } \\
\hline $\begin{array}{l}\text { Baseline GI problems vs no } \\
\text { baseline GI problems }\end{array}$ & $-3.53(-4.953,-2.102)$ & $<0.001$ & $-4.55(-6.125,-2.965)$ & $<0.001$ & $-3.35(-4.981,-1.712)$ & 0.001 \\
\hline GI event BL to M6 & - & - & $-3.85(-5.601,-2.098)$ & $<0.001$ & $-2.79(-4.609,-0.981)$ & 0.003 \\
\hline $\mathrm{GI}(\mathrm{BL} \text { to } \mathrm{M} 6)^{*} \mathrm{GI}(\mathrm{BL}=\mathrm{Y})$ & - & - & $-6.80(-8.695,-4.904)$ & $<0.001$ & $-4.95(-6.905,-2.990)$ & $<0.001$ \\
\hline $\mathrm{GI}(\mathrm{BL} \text { to } \mathrm{M} 6)^{*} \mathrm{GI}(\mathrm{BL}=\mathrm{N})$ & - & - & $-3.14(-5.857,-0.416)$ & 0.024 & $-1.96(-4.780,0.855)$ & 0.172 \\
\hline GI event BL to M12 & - & - & - & - & $-2.98(-4.867,-1.101)$ & 0.002 \\
\hline $\mathrm{GI}(\mathrm{BL}$ to $\mathrm{M} 12) * \mathrm{GI}(\mathrm{BL}=\mathrm{Y})$ & - & - & - & - & $-4.83(-6.864,-2.805)$ & $<0.001$ \\
\hline $\mathrm{GI}(\mathrm{BL}$ to $\mathrm{M} 12) * \mathrm{GI}(\mathrm{BL}=\mathrm{N})$ & - & - & - & - & $-1.99(-4.704,0.728)$ & 0.151 \\
\hline \multicolumn{7}{|l|}{ Emotional status } \\
\hline $\begin{array}{l}\text { Baseline GI problems vs no } \\
\text { baseline GI problems }\end{array}$ & $-5.55(-7.183,-3.915)$ & $<0.001$ & $-5.55(-7.188,-3.912)$ & $<0.001$ & $-4.60(-6.281,-2.914)$ & $<0.001$ \\
\hline GI event $\mathrm{BL}$ to $\mathrm{M} 6$ & - & - & $-5.20(-7.008,-3.386)$ & $<0.001$ & $-5.37(-7.223,-3.510)$ & $<0.001$ \\
\hline $\mathrm{GI}(\mathrm{BL} \text { to } \mathrm{M} 6)^{*} \mathrm{GI}(\mathrm{BL}=\mathrm{Y})$ & - & - & $-8.33(-10.287,-6.371)$ & $<0.001$ & $-7.47(-9.476,-5.461)$ & $<0.001$ \\
\hline $\mathrm{GI}(\mathrm{BL} \text { to } \mathrm{M} 6)^{*} \mathrm{GI}(\mathrm{BL}=\mathrm{N})$ & - & - & $-3.12(-5.935,-0.308)$ & 0.030 & $-3.84(-6.720,-0.952)$ & 0.009 \\
\hline GI event BL to M12 & - & - & - & - & $-5.35(-7.282,-3.417)$ & $<0.001$ \\
\hline $\mathrm{GI}(\mathrm{BL}$ to $\mathrm{M} 12) * \mathrm{GI}(\mathrm{BL}=\mathrm{Y})$ & - & - & - & - & $-7.38(-9.459,-5.303)$ & $<0.001$ \\
\hline $\mathrm{GI}(\mathrm{BL}$ to $\mathrm{M} 12) * \mathrm{GI}(\mathrm{BL}=\mathrm{N})$ & - & - & - & - & $-4.08(-6.866,-1.296)$ & 0.004 \\
\hline \multicolumn{7}{|l|}{ Back pain } \\
\hline $\begin{array}{l}\text { Baseline GI problems vs no } \\
\text { baseline GI problems }\end{array}$ & $-10.11(-12.196,-8.014)$ & $<0.001$ & $-8.66(-10.855,-6.467)$ & $<0.001$ & $-8.50(-10.697,-6.298)$ & $<0.001$ \\
\hline GI event BL to M6 & - & - & $-7.01(-9.438,-4.591)$ & $<0.001$ & $-7.19(-9.618,-4.766)$ & $<0.001$ \\
\hline $\mathrm{GI}(\mathrm{BL} \text { to } \mathrm{M} 6)^{*} \mathrm{GI}(\mathrm{BL}=\mathrm{Y})$ & - & - & $-12.55(-15.174,-9.932)$ & $<0.001$ & $-12.51(-15.133,-9.879)$ & $<0.001$ \\
\hline $\mathrm{GI}(\mathrm{BL} \text { to } \mathrm{M} 6)^{*} \mathrm{GI}(\mathrm{BL}=\mathrm{N})$ & - & - & $-4.98(-8.745,-1.220)$ & 0.010 & $-4.71(-8.474,-0.939)$ & 0.014 \\
\hline GI event BL to M12 & - & - & - & - & $-6.93(-9.452,-4.407)$ & $<0.001$ \\
\hline $\mathrm{GI}(\mathrm{BL}$ to $\mathrm{M} 12) * \mathrm{GI}(\mathrm{BL}=\mathrm{Y})$ & - & - & - & - & $-12.27(-14.994,-9.549)$ & $<0.001$ \\
\hline $\mathrm{GI}(\mathrm{BL}$ to $\mathrm{M} 12) * \mathrm{GI}(\mathrm{BL}=\mathrm{N})$ & - & - & - & - & $-5.21(-8.844,-1.570)$ & 0.005 \\
\hline
\end{tabular}

Results are for new users and experienced users combined. Scores were from the Osteoporosis Assessment Questionnaire (short version)

$B L$ baseline, GI gastrointestinal, M6 month 6, M12 month 12

Increased age was an important predictor of reduced health quality (Online Resource Tables 1, 2, 3, 4, 5). Patients 80 years or older exhibited decreased scores for EQ-5D utility $(-0.04$ to $-0.07, P<0.001)$ and EQ-5D VAS $(-5.80$ to -8.87 , $P<0.001)$ measures, and for the OPAQ physical function ( -13.66 to $-17.01, P<0.001)$, emotional status $(-13.50$ to $-16.86, P<0.001)$, and back pain $(-5.95$ to $-8.61, P \leq 0.001)$ domains, while subjects $70-80$ years of age had significantly lower values on individual measures when compared to those aged 50-60 years of age.

Obese subjects $(\mathrm{BMI} \geq 30)$ exhibited decreased EQ-5D utility $(-0.06$ to $-0.07, P<0.001)$ and EQ-5D VAS scores $(-6.85$ to $-7.06, P<0.001)$, along with reduced OPAQ physical function $(-10.42$ to $-11.83, P<0.001)$, emotional status ( -9.08 to $-10.42, P<0.001)$, and back pain domain scores ( -9.86 to $-10.29, P \leq 0.001$; Online Resource Tables 1, 2, 3, 4,5 ), while overweight subjects (BMI 25-29.99) had significantly lower values on individual EQ-5D utility measures and OPAQ domains when compared with those of normal body weight (BMI 18.5-24.99).

Subjects with osteoporosis of long duration ( $>10$ years) paradoxically demonstrated improved EQ-5D utility scores (0.03 to $0.04, P=0.037-0.002$ ) with improvement also in EQ-5D VAS and individual OPAQ domains at specific time points (Online Resource Tables 1, 2, 3, 4, 5), perhaps reflecting adaptation to their illness or milder disease expression. Prolonged duration of treatment for osteoporosis for more than 5 or 10 years was also associated with improved OPSAT-Q scores (5 years 2.51 to $3.45, P=0.036-0.006$; 10 years 3.41 to $4.09, p=0.017-0.003$; Online Resource Table 6).

Fractures and falls were both associated with a significant reduction of health quality (Online Resource Tables 1, 3, 4) and, in both cases, events occurring prior to baseline and 
Table 4 Least-squares mean differences in OPSAT-Q between patients with and without GI events at baseline, month 6, and month 12

\begin{tabular}{|c|c|c|c|c|c|c|}
\hline \multirow[t]{2}{*}{ Composite satisfaction } & \multicolumn{2}{|l|}{ Baseline } & \multicolumn{2}{|l|}{ Month 6} & \multicolumn{2}{|l|}{ Month 12} \\
\hline & LS mean difference $(95 \% \mathrm{CI})$ & $P$ & LS mean difference $(95 \% \mathrm{CI})$ & $P$ & LS mean difference $(95 \% \mathrm{CI})$ & $P$ \\
\hline $\begin{array}{l}\text { Baseline GI problems vs no } \\
\text { baseline GI problems }\end{array}$ & $-5.88(-7.159,-4.601)$ & $<0.001$ & $-5.89(-7.172,-4.612)$ & $<0.001$ & $-6.46(-7.793,-5.120)$ & $<0.001$ \\
\hline GI event BL to M6 & - & - & $-6.83(-8.241,-5.409)$ & $<0.001$ & $-7.07(-8.539,-5.596)$ & $<0.001$ \\
\hline $\mathrm{GI}(\mathrm{BL}$ to $\mathrm{M} 6) * \mathrm{GI}(\mathrm{BL}=\mathrm{Y})$ & - & - & $-9.21(-10.706,-7.711)$ & $<0.001$ & $-10.20(-11.757,-8.635)$ & $<0.001$ \\
\hline $\mathrm{GI}(\mathrm{BL}$ to $\mathrm{M} 6) * \mathrm{GI}(\mathrm{BL}=\mathrm{N})$ & - & - & $-3.97(-6.164,-1.778)$ & $<0.001$ & $-5.92(-8.205,-3.644)$ & $<0.001$ \\
\hline GI event BL to M12 & - & - & - & - & $-7.88(-9.407,-6.355)$ & $<0.001$ \\
\hline $\mathrm{GI}(\mathrm{BL}$ to $\mathrm{M} 12) * \mathrm{GI}(\mathrm{BL}=\mathrm{Y})$ & - & - & - & - & $-10.59(-12.201,-8.971)$ & $<0.001$ \\
\hline $\mathrm{GI}(\mathrm{BL}$ to $\mathrm{M} 12) * \mathrm{GI}(\mathrm{BL}=\mathrm{N})$ & - & - & - & - & $-7.05(-9.236,-4.857)$ & $<0.001$ \\
\hline
\end{tabular}

Results are for new users and experienced users combined. Scores were from the Osteoporosis Patient Treatment Satisfaction Questionnaire $B L$ baseline, GI gastrointestinal, M6 month 6, M12 month 12

during follow-up combined to substantially reduce values across all measures (Online Resource Tables 1, 2, 3, 4, 5, 6). Fractures reduced quality of life measured by EQ-5D utility $(-0.08, P=0.002-<0.001)$, OPAQ physical function $(-7.26$ to $-10.85, P=0.003-<0.001)$, and OPAQ emotional status domains $(-6.57$ to $-9.95, P=0.009-<0.001)$. The negative influence for falls was observed in EQ-5D utility $(-0.06$ to $-0.08, P<0.001)$, EQ-5D VAS $(-7.87$ to $-9.01, P<0.001)$, OPAQ physical function $(-11.49$ to $-11.80, P<0.001)$, emotional status $(-11.81$ to $-13.15, P<0.001)$, and back pain $(-11.51$ to $-11.98, P<0.001)$ domains, and in OPSAT-Q scores $(-4.27$ to $-4.72, P<0.001)$.

Health quality scores were also generally lower in subjects with other comorbidities, in those receiving nonbisphosphonates and in those with other co-medications (Online Resource Tables 1, 2, 3, 4, 5, 6). There was no significant difference, however, between new users or experienced users in this study.

\section{Discussion}

This analysis of survey responses from European and Canadian women receiving oral prescription treatment for osteoporosis showed that GI events are an independent predictor of reduced HRQoL and lower treatment satisfaction over 1 year of treatment. The results suggest that an ongoing experience of GI events produces a greater and more statistically significant reduction in HRQoL and treatment satisfaction than incident GI events.

Previous studies of the effect of GI events on HRQoL and treatment satisfaction have been conducted in the USA [24, 25]. Binkley et al. reported a subanalysis of an open-label, 6month, multicenter trial in which postmenopausal women taking a weekly bisphosphonate were switched to $150 \mathrm{mg}$ monthly oral ibandronate [25]. GI events were recorded under the new treatment regimen, and HRQoL and treatment satisfaction were assessed concurrently with the OPSAT questionnaire. Among patients reporting experiencing GI side effects at study entry $(N=89), 66$ and $75 \%$ reported decreased frequency of heartburn/acid reflux and stomach upset, respectively, at month 6. Concurrently, the OPSAT quality of life and satisfaction domain scores increased (i.e., improved) by 15.4 and 24.1 points, respectively, in this subset of patients.

Also in the USA, the Prospective Observational Scientific Study Investigating Bone Loss Experience (POSSIBLE) enrolled 5015 postmenopausal women treated for osteoporosis in an ongoing survey [24]. GI side effects were reported by participants at baseline and at 6 and 12 months. EQ-5D utility scores measured at month 6 were not significantly different between patients with and without GI side effects, but global treatment satisfaction scores, measured by the Treatment Satisfaction Questionnaire for Medication at month 6, were significantly lower (i.e., worse) in patients with GI side effects.

One study from Europe has assessed GI events and treatment satisfaction in the same patient population. Turbi et al. examined compliance over 12 months with raloxifene and alendronate in 902 postmenopausal women in Spain [22]. GI adverse events that caused discontinuation of treatment were reported for each treatment group (3.4 and 9.9\%, respectively; $P<0.001$ ), and patient satisfaction was assessed with a single question. Significantly more raloxifene patients were satisfied or very satisfied with their treatment compared to patients taking alendronate (95.7 vs $85.4 \% ; P<0.001)$.

Our study showed that health quality scores were generally lower in subjects receiving non-bisphosphonates. These results vary from the findings of the POSSIBLE US study which reported that women who were new to bisphosphonate therapy at study entry had lower OPAQ-SV physical function scores at study entry than women new to non-bisphosphonate therapy (84.7 and 87.2, respectively; $P=0.03$ ) [24]. However, the POSSIBLE US study reports that women stable on bisphosphonate therapy at study entry had no significant difference in 
HRQoL scores compared with non-bisphosphonate users. It is possible that the differences reported here are a result of methodological differences between the two studies. We analyzed the effect of various covariates on HRQoL among the entire population of treated patients (new and experienced users were not separated for this analysis) while the effect of covariates on HRQoL was assessed separately for new and stable users in the POSSIBLE US manuscript.

The results of the current MUSIC OS-EU analysis are consistent with these previous studies of GI events, HRQoL, and treatment satisfaction, and they improve upon previous studies in several ways. First, MUSIC OS-EU assessed HRQoL and treatment satisfaction separately in patients with or without GI events, a design element missing from earlier studies [22, 25]. This inclusion of a comparator group strengthens the quality of the observed association. Second, our analyses were adjusted for demographic and clinical covariates, such that the results indicate an effect of GI events on HRQoL and treatment satisfaction independent of confounder variables. This effect was quantifiable to the point that differences between the effects of continuing and emergent GI events were observed. Specifically, post-baseline GI events occurring in patients with baseline GI events were associated with changes in the EQ-5D utility scores $\geq 0.07$, the most stringent definition of the MCID [28]. In contrast, post-baseline events occurring in patients without baseline GI events did not produce this MCID (see Table 3). Third, our use of a disease-specific quality of life instrument produced the novel finding that, of the three dimensions of osteoporosis-specific quality of life, back pain is the one that is most affected by GI events. Finally, to our knowledge, MUSIC OS-EU is the first European study to assess the association of GI events with HRQoL in treated osteoporosis patients. Thus, the current study provides information about this association in a heretofore uncharacterized population.

Despite the strengths of the MUSIC OS study, the results of the current analyses are subject to several important limitations. First, due to the design of the study as a patient survey, the accuracy of the findings is limited by patient recall and potentially affected by reporting bias. Second, the leastsquares mean differences were not adjusted for adherence, so some patients may have had GI events not associated with treatment. Third, data collection over the 12-month follow-up period was subject to attrition, so the results do not reflect the experience of patients who discontinued the study. However, the attrition rate was low $(\sim 10 \%)$ and, thus, would not be expected to significantly alter the results. Fourth, the data were pooled from culturally and demographically different countries and therefore reflect the average effect within potentially disparate data. Finally, lack of information about the minimal clinically important difference on the OPAQ and OPSAT questionnaires prevents assessment of the clinical relevance of the effect sizes reported here, and some of the observed differences in quality of life, although statistically significant, may not have been clinically important.

In conclusion, data from treated osteoporosis patients enrolled in MUSIC OS-EU showed that GI events are associated with lower HRQoL and lower satisfaction in osteoporosis patients treated with oral prescription medications. This association was observed at both baseline and 12 months and in both new users and experienced users of prescription treatments. Ongoing GI problems appeared to have a greater effect on HRQoL and treatment satisfaction than GI problems emerging during the study.

Acknowledgements The authors thank the following site investigators for their participation in the study: in Canada, Aliya Khan, Bradley Schweitzer, Kevin Saunders, Miranda Du Preez, Kenneth Bayly, Tersia Lichtenstein, Richard Boroditsky, John S. Corey, Jay Sinha, Jack Kooy, Arun Nayar, Suzanne Arndt, Iman Mohamed, and Wojciech P. Olszynski; in France, Isabelle Legroux, Sandrine Malochet Guinamand, Marie Christine De Vernejoul, Christian Roux, Eric Thomas, Patrice Fardellone, Florence Lévy-Weil, Corina Ursu, Francois Barucq, Olivier Bisch, Philippe Bouche, Nicolas Breton, François Lacoin, Georgios Makridis, Philippe Marmor, Marcel Ruetsch, Denis Taminau, Michel Bismuth, Michel Bourgoin, Didier Sacareau, Christian Scellier, JeanLouis Wurtz, Stephane Le Mouel, Claude Bortolotti, Bernard Lauer, Hervé Amar, and Didier Cadinot; in Italy, Giorgio Gandolini, Mario Barbagallo, Ranuccio Nuti, Marco Di Monaco, Gloria Bonaccorsi, Sandro Giannini, Antonio Del Puente, Salvatore Minisola, Umberto Tarantino, Maria Luisa Brandi, Ombretta Di Munno, Giovanni Mario D’Avola, Maurizio Caminiti, Bruno Frediani, Claudio Marcocci, Franco Grimaldi, Paolo Falaschi, Mario Biondi, Giulia Letizia Mauro, Francesco Paolo Cantatore, and Maurizio Muratore; in Sweden, Karl-Goran Thorngren, and Kristina Akesson; in the Netherlands, M. den Heijer, Neveen A. T. Hamdy, H. R. Franke, Ton Boermans, Adriaan Kooy, and Nicolaas K. Valk; in the UK, Patrick Eavis, Robert Brownlie, Jon Brunskill, Michael Gumbley, Richard Gaunt, Jennifer Litchfield, G. D. Martin, Boo McConnell, Terry McCormack, Narayanan Annamalai, Devi Srinivasan, Amrit Takhar, Trevor Gooding, Paul Conn, Ian Parker, Michael Redmond, John Calvert, T. W. S. Cookson, Paul Ainsworth, Amardeep Heer, and Nell Wyatt.

The authors also thank Anna Kaufman, MPH, and Melissa Stauffer, $\mathrm{PhD}$, in collaboration with ScribCo, for medical writing assistance.

The study was funded by Merck \& Co., Inc.

\section{Compliance with ethical standards}

Conflicts of interest A. Modi and S. Sen are employees of Merck \& Co., Inc. and own stock in the company. J.D. Adachi has received grant support and speaker honorarium from Actavis, Amgen, Eli Lilly, Merck \& Co., Inc. and Novartis. J.D. Adachi is a consultant for Amgen, Eli Lilly, and Merck \& Co., Inc. S. Adami has received consulting honorarium from Merck \& Co., Inc. and served as a board member for Merck \& Co., Inc. B. Cortet has received research grants, consulting honorarium, and/or speaker honorarium from Amgen, Expanscience, Ferring, Eli Lilly, Merck \& Co., Inc., Merck Sharp \& Dohme, Medtronic, and Roche diagnostics. A.L. Cooper has received research grants, advisory board and/or speaker honorarium from Consilient Health and Internis Pharmaceuticals. P. Geusens has received research grants, advisory board and/or speaker honorarium from Pfizer, Abbott, Eli Lilly, Amgen, Merck Sharp \& Dohme, Will Pharma, Roche, UCB pharmaceuticals, BristolMyers Squibb, and Novaritis. D. Mellström has received consulting honorarium from Merck Sharp \& Dohme. J.P. Weaver is an employee of Merck \& Co., Inc. J.P. van den Bergh is a paid consultant at Amgen 
and Will Pharma. J.P. van den Bergh has received research grants and speaker honorarium from Amgen, Will Pharma, and Eli Lilly. P.A. Keown is the director of and employed by Syreon Corporation and has received financial remuneration from Merck \& Co., Inc. to conduct the study, participate in study meetings, and perform statistical analysis. S. Sajjan was an employee of Merck \& Co., Inc. and owned stock in the company at the time of the study.

Open Access This article is distributed under the terms of the Creative Commons Attribution-NonCommercial 4.0 International License (http:// creativecommons.org/licenses/by-nc/4.0/), which permits any noncommercial use, distribution, and reproduction in any medium, provided you give appropriate credit to the original author(s) and the source, provide a link to the Creative Commons license, and indicate if changes were made.

\section{References}

1. Hernlund E, Svedbom A, Ivergard M, Compston J, Cooper C, Stenmark J, McCloskey EV, Jonsson B, Kanis JA (2013) Osteoporosis in the European Union: medical management, epidemiology and economic burden. A report prepared in collaboration with the International Osteoporosis Foundation (IOF) and the European Federation of Pharmaceutical Industry Associations (EFPIA). Arch Osteoporos 8:136. doi:10.1007/s11657-013-0136-1

2. Leslie WD, Tsang JF, Lix LM (2008) Effect of total hip bone area on osteoporosis diagnosis and fractures. J Bone Miner Res 23: 1468-1476. doi:10.1359/jbmr.080416

3. Johnell O, Kanis JA (2006) An estimate of the worldwide prevalence and disability associated with osteoporotic fractures. Osteoporos Int 17:1726-1733. doi:10.1007/s00198-006-0172-4

4. Cauley JA (2013) Public health impact of osteoporosis. J Gerontol A Biol Sci Med Sci 68:1243-1251. doi:10.1093/gerona/glt093

5. Guillemin F, Martinez L, Calvert M, Cooper C, Ganiats T, Gitlin M, Horne R, Marciniak A, Pfeilschifter J, Shepherd S, Tosteson A, Wade S, Macarios D, Freemantle N (2013) Fear of falling, fracture history, and comorbidities are associated with health-related quality of life among European and US women with osteoporosis in a large international study. Osteoporos Int 24:3001-3010. doi:10.1007/ s00198-013-2408-4

6. Roux C, Wyman A, Hooven FH, Gehlbach SH, Adachi JD, Chapurlat RD, Compston JE, Cooper C, Diez-Perez A, Greenspan SL, Lacroix AZ, Netelenbos JC, Pfeilschifter J, Rossini M, Saag KG, Sambrook PN, Silverman S, Siris ES, Watts NB, Boonen S, investigators G (2012) Burden of non-hip, nonvertebral fractures on quality of life in postmenopausal women: the Global Longitudinal Study of Osteoporosis in Women (GLOW). Osteoporos Int 23:2863-2871. doi:10.1007/s00198012-1935-8

7. Palacios S, Neyro JL, Fernandez de Cabo S, Chaves J, Rejas J (2014) Impact of osteoporosis and bone fracture on health-related quality of life in postmenopausal women. Climacteric 17:60-70. doi: $10.3109 / 13697137.2013 .808182$

8. Papaioannou A, Kennedy CC, Ioannidis G, Sawka A, Hopman WM, Pickard L, Brown JP, Josse RG, Kaiser S, Anastassiades T, Goltzman D, Papadimitropoulos M, Tenenhouse A, Prior JC, Olszynski WP, Adachi JD (2009) The impact of incident fractures on health-related quality of life: 5 years of data from the Canadian Multicentre Osteoporosis Study. Osteoporos Int 20:703-714. doi: 10.1007/s00198-008-0743-7

9. Salaffi F, Cimmino MA, Malavolta N, Carotti M, Di Matteo L, Scendoni P, Grassi W (2007) The burden of prevalent fractures on health-related quality of life in postmenopausal women with osteoporosis: the IMOF study. J Rheumatol 34:1551-1560

10. Sanfelix-Genoves J, Hurtado I, Sanfelix-Gimeno G, Reig-Molla B, Peiro S (2011) Impact of osteoporosis and vertebral fractures on quality-of-life. A population-based study in Valencia, Spain (the FRAVO study). Health Qual Life Outcomes 9:20. doi:10.1186/ 1477-7525-9-20

11. Strom O, Borgstrom F, Zethraeus N, Johnell O, Lidgren L, Ponzer S, Svensson O, Abdon P, Ornstein E, Ceder L, Thorngren KG, Sernbo I, Jonsson B (2008) Long-term cost and effect on quality of life of osteoporosis-related fractures in Sweden. Acta Orthop 79: 269-280. doi:10.1080/17453670710015094

12. Si L, Winzenberg TM, de Graaff B, Palmer AJ (2014) A systematic review and meta-analysis of utility-based quality of life for osteoporosis-related conditions. Osteoporos Int 25:1987-1997. doi:10.1007/s00198-014-2636-2

13. Wilson S, Sharp CA, Davie MW (2012) Health-related quality of life in patients with osteoporosis in the absence of vertebral fracture: a systematic review. Osteoporos Int 23:2749-2768. doi:10.1007/ s00198-012-2050-6

14. Cvijetic S, Mestrovic T, Crkvenac A, Davila S, Korsic M (2002) Quality of life in osteoporotic patients with hip fracture and without fracture. Arh Hig Rada Toksikol 53:257-262

15. Dennison EM, Syddall HE, Statham C, Aihie Sayer A, Cooper C (2006) Relationships between SF-36 health profile and bone mineral density: the Hertfordshire cohort study. Osteoporos Int 17: 1435-1442. doi:10.1007/s00198-006-0151-9

16. Lau AN, Ali SH, Sawka AM, Thabane L, Papaioannou A, Gafni A, Adachi JD (2008) Improvement in health-related quality of life in osteoporosis patients treated with teriparatide. BMC Musculoskelet Disord 9:151. doi:10.1186/1471-2474-9-151

17. Kastelan D, Vlak T, Lozo P, Gradiser M, Mijic S, Nikolic T, Miskic B, Car D, Tajsic G, Dusek T, Jajic Z, Grubisic F, Poljicanin T, Bakula M, Dzubur F, Strizak-Ujevic M, Kadojic M, Radman M, Vugrinec M, Kuster Z, Pekez M, Radovic E, Labar L, CrncevicOrlic Z, Korsic M (2010) Health-related quality of life among patients with postmenopausal osteoporosis treated with weekly and monthly bisphosphonates. Endocr Res 35:165-173. doi:10.3109/ 07435800.2010 .505218

18. Marquis P, Roux C, de la Loge C, Diaz-Curiel M, Cormier C, Isaia G, Badurski J, Wark J, Meunier PJ (2008) Strontium ranelate prevents quality of life impairment in post-menopausal women with established vertebral osteoporosis. Osteoporos Int 19:503-510. doi: 10.1007/s00198-007-0464-3

19. Panico A, Lupoli GA, Marciello F, Lupoli R, Cacciapuoti M, Martinelli A, Granieri L, Iacono D, Lupoli G (2011) Teriparatide vs. alendronate as a treatment for osteoporosis: changes in biochemical markers of bone turnover, BMD and quality of life. Med Sci Monit 17:Cr442-Cr448

20. Kothawala P, Badamgarav E, Ryu S, Miller RM, Halbert RJ (2007) Systematic review and meta-analysis of real-world adherence to drug therapy for osteoporosis. Mayo Clin Proc 82:1493-1501. doi:10.1016/s0025-6196(11)61093-8

21. Ringe JD, Moller G (2009) Differences in persistence, safety and efficacy of generic and original branded once weekly bisphosphonates in patients with postmenopausal osteoporosis: 1year results of a retrospective patient chart review analysis. Rheumatol Int 30:213-221. doi:10.1007/s00296-009-0940-5

22. Turbi C, Herrero-Beaumont G, Acebes JC, Torrijos A, Grana J, Miguelez R, Sacristan J, Marin F (2004) Compliance and satisfaction with raloxifene versus alendronate for the treatment of postmenopausal osteoporosis in clinical practice: an open-label, prospective, nonrandomized, observational study. Clin Ther 26:245-256

23. Hamilton B, McCoy K, Taggart H (2003) Tolerability and compliance with risedronate in clinical practice. Osteoporos Int 14:259262. doi:10.1007/s00198-002-1370-3 
24. Woo C, Gao G, Wade S, Hochberg MC (2010) Gastrointestinal side effects in postmenopausal women using osteoporosis therapy: 1year findings in the POSSIBLE US study. Curr Med Res Opin 26:1003-1009. doi:10.1185/03007991003633603

25. Binkley N, Martens MG, Silverman SL, Derman RJ, Greenwald M, Kohles JD, Bachmann GA (2009) Improved GI tolerability with monthly ibandronate in women previously using weekly bisphosphonates. South Med J 102:486-492. doi:10.1097/SMJ. 0b013e31819ed0dd

26. Modi A, Sen S, Adachi JD, Adami S, Cortet B, Cooper AL, Geusens P, Mellstrom D, Weaver JP, van den Bergh JP, Nguyen AM, Keown PA, Leung AT, Sajjan S (2015) Rationale and design of MUSIC OS-EU: an international observational study of the treatment of postmenopausal women for osteoporosis in Europe and Canada. Clin Exp Rheumatol 33:537-544

27. Rabin R, de Charro F (2001) EQ-5D: a measure of health status from the EuroQol group. Ann Med 33:337-343

28. Walters SJ, Brazier JE (2005) Comparison of the minimally important difference for two health state utility measures: EQ-5D and SF6D. Qual Life Res 14:1523-1532
29. Sullivan PW, Lawrence WF, Ghushchyan V (2005) A national catalog of preference-based scores for chronic conditions in the United States. Med Care 43:736-749

30. Silverman S (2000) The Osteoporosis Assessment Questionnaire (OPAQ): a reliable and valid disease-targeted measure of healthrelated quality of life (HRQOL) in osteoporosis. Qual Life Res 9: 767-774. doi:10.1023/A:1008934208764

31. Flood EM, Beusterien KM, Green H, Shikiar R, Baran RW, Amonkar MM, Cella D (2006) Psychometric evaluation of the Osteoporosis Patient Treatment Satisfaction Questionnaire (OPSAT-Q), a novel measure to assess satisfaction with bisphosphonate treatment in postmenopausal women. Health Qual Life Outcomes 4:42. doi:10.1186/1477-7525-4-42

32. Modi A, Sen S, Adachi JD, Adami S, Cortet B, Cooper AL, Geusens P, Mellstrom D, Weaver J, van den Bergh JP, Nguyen AM, Sajjan S, Group M-OS (2016) Gastrointestinal symptoms and association with medication use patterns, adherence, treatment satisfaction, quality of life, and resource use in osteoporosis: baseline results of the MUSIC-OS study. Osteoporos Int 27:1227-1238. doi:10.1007/s00198-015-3388-3 